\title{
Au/Titania Composite Nanoparticle Arrays with Controlled Size and Spacing by Organic-Inorganic Nanohybridization in Thin Film Block Copolymer Templates
}

\author{
Xue Li, ${ }^{+}$Jun Fu, ${ }^{\dagger}$ Martin Steinhart, ${ }^{\circledR}$ Dong Ha Kim, ${ }^{+, * \times}$ and Wolfgang Knoll \\ ${ }^{+}$Max Planck Institute for Polymer Research, Ackermanweg 10, 55128 Hainz, Germany \\ ${ }^{\ddagger}$ School of Chemistry and Chemical Engineering, University of Jinan, Jinan 250022, P. R. China \\ Aar Planck Institute of Hicrostructure Phusics, Weinberg 2, 06120 Halle, Germany \\ *Division of Nano Sciences and Department of Chemistry, Ewha Womans Lniversity, Seoul 120-750, Korea \\ ${ }^{*}$ E-mail: dhtimatewha.ackr \\ Received February 22, 2007
}

\begin{abstract}
A simple approach to prepare arrays of $\mathrm{Au} / \mathrm{TiO}$ z composite nanoparticles by using Au-loaded block copolymers as templates combined with a sol-gel process is described. The organic-inorganic hybrid films with closely packed inorganic nanodomains in organic matrix are produced by spin coating the mixtures of polysty'rene-block-poly (ethylene oxide) (PS- $b$ - $\mathrm{PEO}$ )/ $\mathrm{HAuCl}_{4}$ solution and sol-gel precursor solution. After removal of the organic matrix with deep UV irradiation, arrays of $\mathrm{Au} / \mathrm{TiO}_{2}$ composite nanoparticles with different compositions or particle sizes can be easily produced. Different photoluminescence (PL) emission spectra from an organic-inorganic hybrid film and arrays of $\mathrm{Au} / \mathrm{TiO}$, composite nanoparticles indicate that $\mathrm{TiO}_{2}$ and $\mathrm{Au}$ components exist as separate state in the initial hybrid film and form composite nanoparticles after the removal of the block copolymer matrix
\end{abstract}

Key Words : $\mathrm{Au} / \mathrm{TiO}_{2}$ nanoparticle, Block copoly mer. Sol-gel. Organic-inorganic hybrid. Photoluminescence

\section{Introduction}

Metal/semiconductor oxide composite nanoparticles are extremely attractive because they exhibit novel optical. electrical. magnetic. and chemical properties that are not found in the individual components ${ }^{1-3}$ The possible applications include nanoelectronics device. catalysis. nonlinear optical devices. etc. ${ }^{1-5}$ Titanium dioxide $\left(\mathrm{TiO}_{2}\right)$ is one of the most widely studied semiconductor materials due to the wealth of useful applications. ${ }^{1.66}$ Recently. TiO-based sy'stems containing transition metal ions and noble metals have been investigated extensively to improve the efficiency of the photocatalytic and photoelectrochemical responses. i.:

Several routes to the fabrication of thin films containing nanoparticles of semiconductors and metals have been suggested including physical tecluniques. ${ }^{78}$ chemical methods. ${ }^{910}$ or a two-step method consisting of Au(III)-complex chemisorption and subsequent photoreduction. ${ }^{2 \mathrm{c}}$ Microstructured $\mathrm{Au} / \mathrm{TiO}$, model catalysts are also produced by combining optical lithography methods for microstructuring with ultrahigh vacuum evaporation for Au nanoparticle deposition. ${ }^{11}$

In many applications. the ability to use nanoparticle properties for device fabrication will require the formation of highly ordered arrays of nanoparticles. '2 Several approaches have been reported to generate arrays of composite nanoparticles. ${ }^{13}$ However. it is challenging to control the funal morphology and composition of the produced nanostructures. There is still a strong demand for simple. facile routes to fabricate arrays of the metal/semiconductor composite nanostnuctures with different size. spacing or composition.

The self-assembly of diblock copolymers has been recognized as an attractive platform toward highly ordered. periodic nanoscale structures. ${ }^{1+17}$ An increasing number of novel functional nanostructures have been reported from this unique class of polymers. ${ }^{18-23}$ for instance. magnetic storage media. ${ }^{24}$ resists in microelectronics. ${ }^{25}$ photonic band gap materials. ${ }^{26}$ planar optical waveguides. ${ }^{27}$ etc. In particular. it has also been shown that hexagonally ordered 2-dimensional (2D) arrays of metallic. inorganic. semiconductor, and metal/ semiconductor nanoparticles could be generated using block copolymer as templates ${ }^{2-31}$

Recently, thin films of amphiphilic poly(styrene-blockethylene oxide) copolymer (PS- $b$-PEO) with cylindrical PEO microdomains aligned perpendicular to the substrate surface have attracted increasing attention as scaffolds to produce array's of inorganic nanostructures. ${ }^{30.31}$ Combining sol-gel (SG) process. organic-inorganic hybrid nanostructures can be fabricated with $\mathrm{TiO}_{2}$ selectively incorporated into the PEO microdomains. ${ }^{31}$ In this work, we extend this methodology to produce arrays of composite $\mathrm{Al} / \mathrm{TiO}$, composite nanoparticles using Au precursor-loaded block copolymer micelles as templates. Although sol-gel chemistry using block copolymers as structure-directing agent has been extensively exploited to generate highly ordered mesoporous materials. ${ }^{32}$ no experimental reports have yet been made concerning arrays of metal/ semiconductor composite nanoparticles. The present approach involves the fabrication of organic-inorganic hybrid nanocomposite films with $\mathrm{TiO}_{2}$ and Au precursors incorporated into PEO mocrodomains. Specifically, we show that the lateral scale of the arrays of composite nanoparticles. i.e. the size of each nanoparticle and spacing. as well as the composition can be finely tuned on the nanometer scale by controlling the relative amount of sol-gel precursor to block copolymer and the loading ratio of $\mathrm{HAuCl}_{4}$ to $\mathrm{EO}$ units in 
(a)

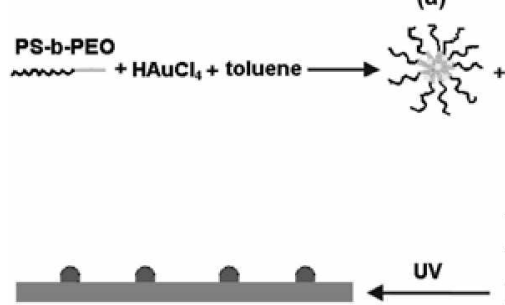

(d) (b)

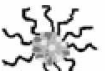
$5\}^{2}$ spin-coating

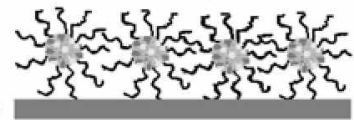

(c)

Figure 1. Schematic illustration of the process to produce arrays of $\mathrm{Au} / \mathrm{TiO}_{2}$ composite nanoparticles. (a) Formation of All-loaded micellar solution of PS- $b$-PEO block copolymers in toluene. (b) The Au-loaded micellar solution is mixed with the desired anount of sol-gel precursor solution; titania precursor incorporates into the $\mathrm{PEO} / \mathrm{HAllCl}_{4}$ domains. (c) Preparation of an organic-inorganic hybrid film by spin coating the mixed solution on a silicon substrate. (d) Arrays of pure $\mathrm{Au} / \mathrm{TiO}_{2}$ composite nanoparticles obtained after removal of the block copolymer template.

the block copolymer. The overall procedure for the generation of $\mathrm{Au} / \mathrm{TiO}_{2}$ composite nanoparticles arrays is schematically illustrated in Figure 1.

\section{Experimental Part}

Materials. Asymmetric poly (styrene-block-ethylene oxide) block copolymer (PS- $b$-PEO) with a polydispersity index of 1.05 was purchased from Polymer Source. Inc. The number average molecular weights of PS and PEO blocks are $19000 \mathrm{~g} / \mathrm{mol}$ and $6400 \mathrm{~g} / \mathrm{mol}$, respectively. Titanium tetra-isopropoxide (TTIP. 97\%). and tetrachloroauric (III) acid $\left(\mathrm{HAuCl}_{4} \times \mathrm{HH}_{2} \mathrm{O} . \mathrm{M}_{w}=333.79\right)$ were purchased from Aldrich and used as received. Analytical grade toluene. isopropanol and hydrochloric acid $(\mathrm{HCl}, 37 \%)$ were purchased from Laborbedarf $\mathrm{GmbH}$.

Substrates. Silicon (Si) wafers with a native oxide laver (ca. $2.5 \mathrm{~cm} \times 2.5 \mathrm{~cm}$ ) were cleaned in a piranha solution $(70 /$ $30 \mathrm{v} / \mathrm{v}$ of concentrated $\mathrm{H}_{2} \mathrm{SO}_{4} / 30 \% \mathrm{H}_{2} \mathrm{O}_{2}$. Caution! Piranha solution reacts violently with organic compounds and should not be stored in closed containers.) at $80^{\circ} \mathrm{C}$ for $30 \mathrm{~min}$. thoroughly rinsed with Milli-Q water and then blown dry with nitrogen gas.

Film Preparation. A $1.0 \mathrm{wt} \%$ toluene solution of the PS$b$-PEO diblock copolymer containing an equivalent amount of $\mathrm{HAuCl}_{4}$ precursor was stirred for at least $12 \mathrm{~h}$ to make a clear solution. The molar ratio of $\mathrm{HAuCl}_{4} / \mathrm{EO}$ was adjusted to 0.1. Sol-gel (SG) precursor solutions were prepared as described previously. ${ }^{31}$ The desired amount of sol-gel precursor solution was added into Au-loaded PS- $b$-PEO solution and stirred for $30 \mathrm{~min}$ to make the initial common solution. denoted PS- $b$-PEO/HAuCl/ $/ \mathrm{SG}$ The amount of precursors relative to the block copolymers $(\varphi)$ was adjusted from 7.0 to $20.0 \mathrm{w} / \mathrm{\%} \%$

The hy brid inorganic-organic films were produced simply by spin coating the common solution on a piece of $\mathrm{Si}$ substrate at $2500 \mathrm{rpm}$. To adjust the film thickness. the initial mixed solution was diluted with toluene. The obtained films were dried under ambient condition to induce crosslinking

of the sol-gel precursor. The film thickness was about $48 \mathrm{~nm}$ as measured by a surface profiler (Tencor-10).

In order to remove the block copolymer template and reduce $\mathrm{HAuCl}_{4}$ into metallic Aul the films were treated with deep UV irradiation in air $(\lambda=254 \mathrm{~nm}$. 30W $)$ for 2 days. ${ }^{33}$

Characterization. AFM height and phase contrast images were obtained using a Digital Instruments Dimension 3100 scanning force microscope in the tapping mode with Olympus cantilever with spring constants ranging between 33.2 and $65.7 \mathrm{~N} / \mathrm{m}$ and a resonant frequency of $277.3-346.3 \mathrm{~Hz}$ (as specified by the manufacturer). Field emission scanning electron microscopy (FESEM) images were obtained with a LEO 1530 "Gemini". The average diameters of the inorganic domains containing titania and gold were determined Image J program $(\mathrm{NIH})$. The center-to-center distance between domains were calculated from AFM images using Nanoscope software (Nanoscope III 5.12r3). XPS measurements were performed on a Perkin-Elmer-Physical Electronics 5100 with $\mathrm{Mg} \mathrm{K} \alpha$ excitation ( $400 \mathrm{~W}$ ). Spectra were obtained at a takeoff angle of $15^{\circ}$. Photoluminescence (PL) spectra were measured using a SPEX FLUOROLOG II (212) instrument at an excitation wavelength of $350 \mathrm{~nm}$ and $260 \mathrm{~cm}$. The hybrid films were treated at $90^{\circ} \mathrm{C}$ for $\mathrm{l} \mathrm{h}$ in vacuum or with UV light for 2 days in air before PL measurement.

\section{Results and Discussion}

The AFM height images of the hybrid films spin-coated from the initial PS- $b$-PEO/HAuCl$/ / S G$ mixed solutions with different amount of SG precursor are shown in Figure 2. The
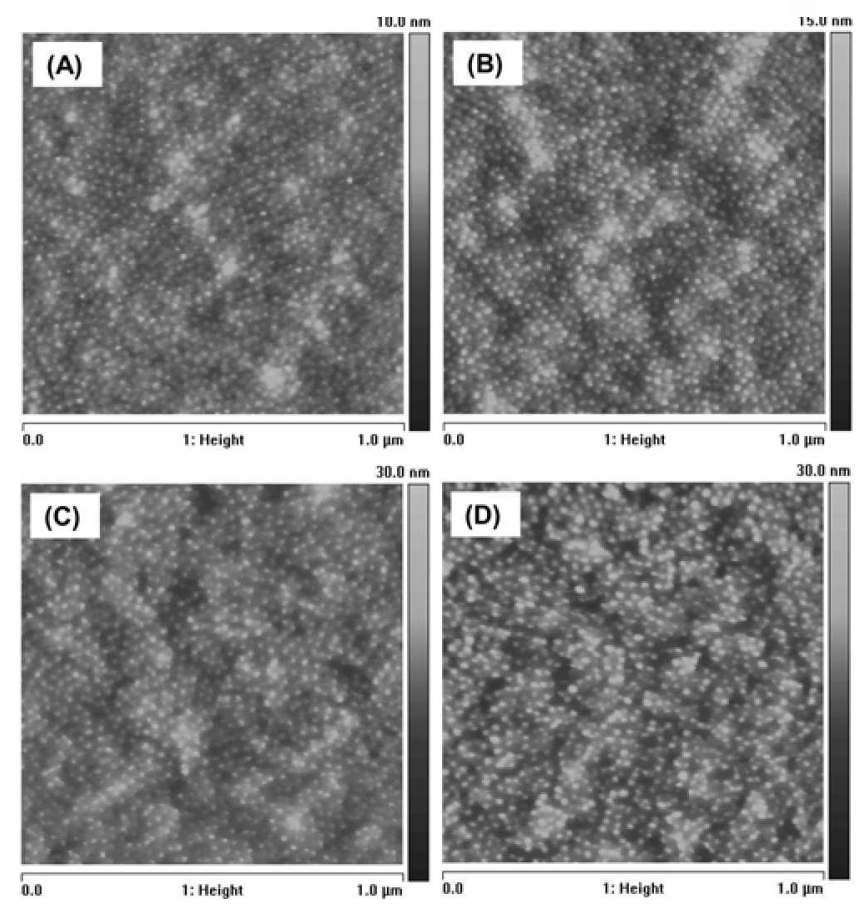

Figure 2. AFM height contrast images of the surfaces of the spincoated PS- $b$-PEO/HAuCl./SG films with different amount of solgel precursors: (a) $7.0 \%$; (b) $10.0 \%$; (c) $15.0 \%$ : (d) $20.0 \%$. The film thickness is about $48 \mathrm{~nm}$. The images show 1 tam $\times 1$ tam area on the surface. 
brighter regions in the phase inages correspond to the inorganic donains. ${ }^{21,31}$ Highly dense arrays of inorganic nanoparticles in organic matrix were observed when $\varphi$ increases from $7.0 \%$ to $20.0 \%$, which is similar to the results obtained in the All-free PS- $b$-PEO/SG sy stem. ${ }^{31}$ One can see from Figure 2 that the hybrid film with a SG precursor amount of $\varphi \sim 10 \%$ exhibits well ordered. hexagonal packing with a relatively uniform particle size. Such an optimun SG content in terms of the long-range order was also observed in our previous work. ${ }^{j 1}$ The surface morphologies of the hybrid films were independent of the film thickness in the range of $10-50 \mathrm{~lm}$ explored in this study.

Compared to the previous PS- $b$-PEO/SG system, ${ }^{31}$ the addition of $\mathrm{HAuCl}_{4}$ has a noticeable influence on the trend of the lateral dimension of the inorganic domains at the suface of a lybrid PS- $b$ - $\mathrm{PEO} / \mathrm{HAuCl} / \mathrm{SG}$ film with increasing $\varphi$. Figure 3 shows the SEM images of about $12 \mathrm{~nm}$ thick PS$b-\mathrm{PEO} / \mathrm{HAuCl} / \mathrm{SG}$ films with different amounts of SG precursors on Si substrates. The average domain size $(D)$ and the center-to-center distance $\left(d_{-0}\right)$ are displayed in Figure 3e. The $\mathrm{D}$ values are about $10.5 \pm 3.5$. 13.4 \pm 2.4 . $15.1 \pm 3.2$. and $15.6 \pm 3.6 \mathrm{~nm}$ and the $d w$. values are about 25.0 .25 .6 .26 .4 and $27.8 \mathrm{~nm}$. for samples with $\rho$ values of 7.0. $10.0,15.0$ and $20 \%$ respectively. Both $D$ and $d_{C . C}$ increase monotonically with increasing $\varphi$. which are different from the results observed in the PS- $b$-PEO/SG system. ${ }^{31}$ This result may be explained as follows: PS- $b$-PEO can form micelles in a non-polar solvent (such as toluene used in this study). With the addition of Au precursor $\mathrm{HAuCl}_{4}$, it forms a complex with the EO units. ${ }^{280}$ Titania SG precursor is composed of TTIP. $\mathrm{HCl}(37 \%)$. toluene and isopropanol. When the SG precursor is added into the $\mathrm{PS}-b-\mathrm{PEO} / \mathrm{HAuCl}_{+}$ solution. isopropanol and small anounts of water are easily absorbed into the micellar cores due to the existence of
$\mathrm{HAuCl}_{4}$ in the PEO domains. Since this effect would cause the aggregation number of the block copolymer micelles to increase, ${ }^{3-4}$ it is reasonable to deduce that the micelle size increases with increasing $p$. On the other hand. the Au precursors uniformly distribute inside $\mathrm{PEO}$ domains to form composites with the $S G$ precursors that help to prevent the $S G$ precursors from self-aggregation. This effect may preclude the macro-phase separation of SG precursors from the BCP domains. Therefore. the domain size of the $\mathrm{TiO}_{2}$ nanoparticles increases with increasing $\varphi$ after SG incorporates into the $P E O$ domains selectively due to strong interaction between the SG precursor and the $\mathrm{PEO}$ domains containing $\mathrm{HAuCl}_{4}$ precursor. With the assumption that the SG precursor is uniformly distributed in the micelles domains, ${ }^{3.1}$ the centerto-center distance $\left(d_{c}\right)$ will also increase due to the increase of the micelle size with increasing $p$. When the SG content is less than $p \sim 20 \%$, the PEO domains could include all the SG precursor molecules, while macrophase separation occurred with a further increase of $\rho$ to $30 \%$.

The chemical identity of the surface of a spin-coated PS- $b$ $\mathrm{PEO} / \mathrm{HAuCl}_{4} / \mathrm{SGl} 0$ film was investigated by XPS analy sis. The survey spectrum clearly reveals that Ti. O. C. and Au elements exist in the hybrid film. as shown in Figure 4a. Figure $4 \mathrm{~b}$ is the high resolution $\mathrm{Ti}_{2 \mathrm{p}}$ spectrum and the characteristic peaks of $\mathrm{Ti}_{\mathrm{p}_{\mathrm{p}} z_{2}}$ and $\mathrm{Ti}_{\mathrm{p}_{\mathrm{p}}: 2}$ in $\mathrm{TiO}_{2}$ were observed at $459.4 \mathrm{eV}$ and 465.2 . respectively. ${ }^{35}$ The peaks at $457.6 \mathrm{eV}$ and $455.3 \mathrm{eV}$ due to other titania species such as $\mathrm{Ti}_{\mathrm{F}_{\mathrm{p}}: 2}$ in $\mathrm{Ti}_{2} \mathrm{O}_{3}$ or $\mathrm{TiO}$ were not observed. ${ }^{36}$ Therefore. it is concluded from the XPS results that the titania nanoparticles in the hybrid film are mainly composed of $\mathrm{TiO}_{2}$.

In order to generate arrays of pure $\mathrm{Aw} / \mathrm{TiO}_{2}$ composite nanoparticles on the silicon substrate from the initial hybrid organic-inorganic films. the block copolymer templates were removed by deep UV irradiation. $\mathrm{HAuCl}_{4}$ is reduced simul-
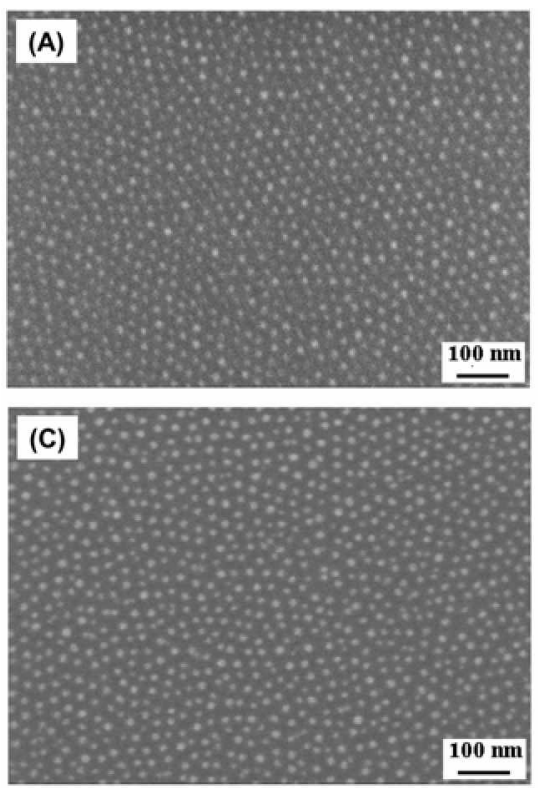
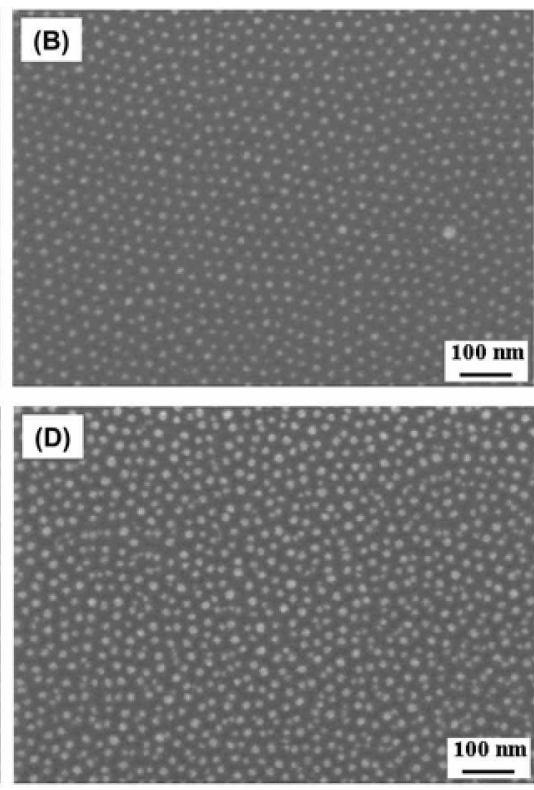

(E)

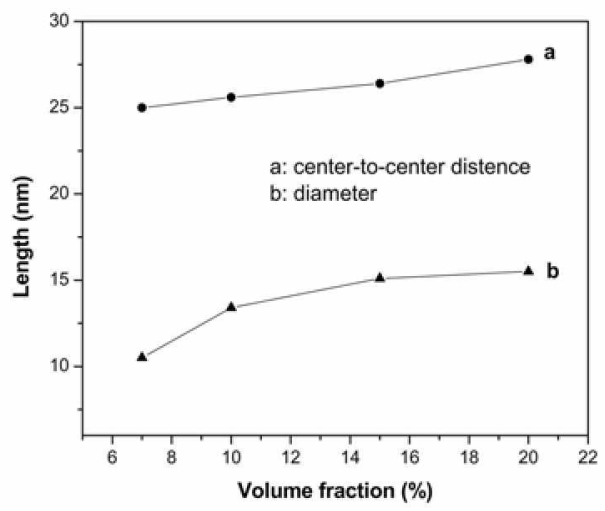

Figure 3. FESEM inages of the spin-coated PS- $b$-PEO/HAuCl/SG films with difterent amount of sol-gel precursors: (a) $7.0 \%$; (b) $10.0 \%$; (c) $15.0 \%$; (d) $20.0 \%$. The film thickness is about $12 \mathrm{~nm}$. (e) The average diameter of the inorganic domains, $D$, and the center-to-center distance between them, $d_{c-c}$, as a function of the amount of sol-gel precursors. '1 he scale bar at lower left of each SEM image represents 100 nm. 

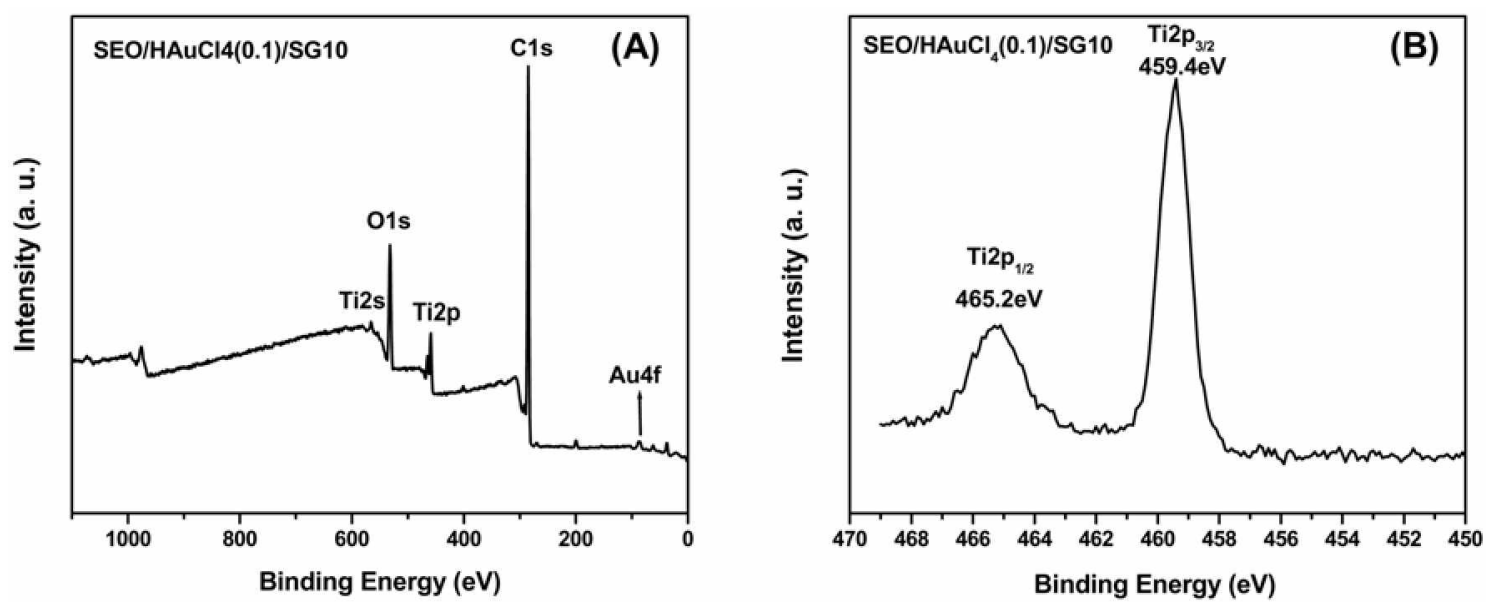

Figure 4. XPS survey (a) and high-resolution XPS Ti $i_{2 p}$ spectra (b) of the surface of a spin-coated PS- $b$-PEO/HAuCl/SGlo film.

taneously into metallic Au during this irradiation process. ${ }^{33.37}$ It should be noted that arrays of composite nanoparticles could be obtained only from hybrid micellar films of PS- $b$ $\mathrm{PEO} / \mathrm{HAuCl}_{4} / \mathrm{SG}$ of the order of one monolayer thickness because the inorganic dontains in thicker films (e.g. $48 \mathrm{~nm}$ ). which do not form cylinders perpendicular to the substrate surface. collapse to form irregular arrays after matrix removal. Figure 5 shows the SEM image of arrays of $\mathrm{Al} /$ $\mathrm{TiO}_{2}$ composite nanoparticles obtained from the hybrid films of about $12 \mathrm{~nm}$ thickness obtained by UV exposure in air for 2 days. The average particle size is measured to be $15.7 \pm$ $3.5 \mathrm{~nm}$. $18.1 \pm 2.8 \mathrm{~lm}, 20.9 \pm 2.8 \mathrm{lml}$. and $20.2 \pm 4.5 \mathrm{~lm}$ for samples with $\varphi$ values of $7.0,10.0,15.0$. and $20 \%$. respectively. XPS measurement was also performed to determine the chemical composition of the resulting composite nanoparticles. The spectrum of $\mathrm{Ti}_{2, j}$, from the film after removal of the block copolymer is similar to that from the hybrid film (Figure 3b). Characteristic peaks of $\mathrm{Au}^{13}$ were observed at binding energies of $87.5 \mathrm{eV}\left(\mathrm{Au}_{4} \mathrm{f}_{5 \mathrm{c}}\right)$ and 84.0 $\mathrm{eV}\left(\mathrm{Au} 4 \mathrm{f}_{7: 2}\right){ }^{35}$ Therefore, it is concluded that these nanoparticles contain metallic Au. More in-depth analysis of the individual nanoparticle is in progress by high-resolution transmission electron microscopy.

We explore the photoluminescence (PL) properties of the hybrid PS- $b$-PEO/HAuCl$/ 4 / S G$ films and arrays of $\mathrm{Au} / \mathrm{TiO}_{2}$ composite nanoparticles with an excitation wavelength of 350 nim and $260 \mathrm{~nm}$. respectively. Figure 6 shows the representative PL spectra from a spin-coated film and arrays of $\mathrm{Au} /$ $\mathrm{TiO}_{2}$ nanoparticles with $\varphi$ value of $10.0 \%$. It can be seen from Figure $6 a$ and $b$. that the initial hybrid samples exhibit the broadband PL with main peak located at about $420 \mathrm{~nm}$ under photoexcitation at $350 \mathrm{~nm}$. which can be attributed to
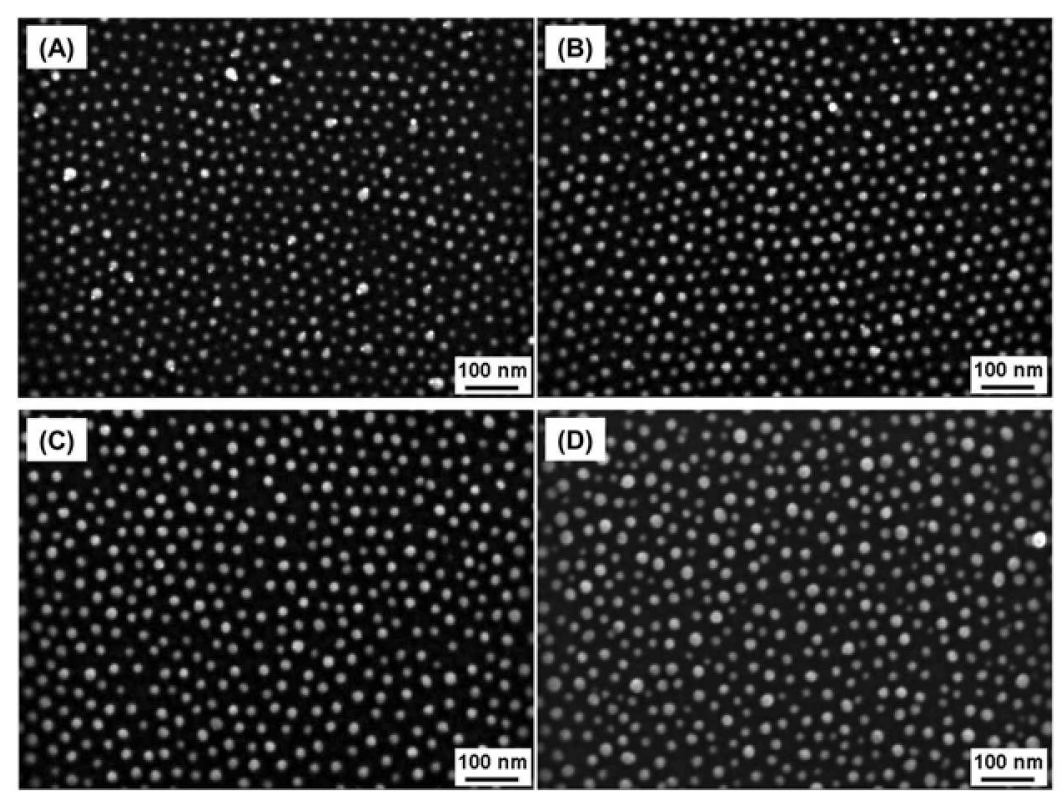

(E)

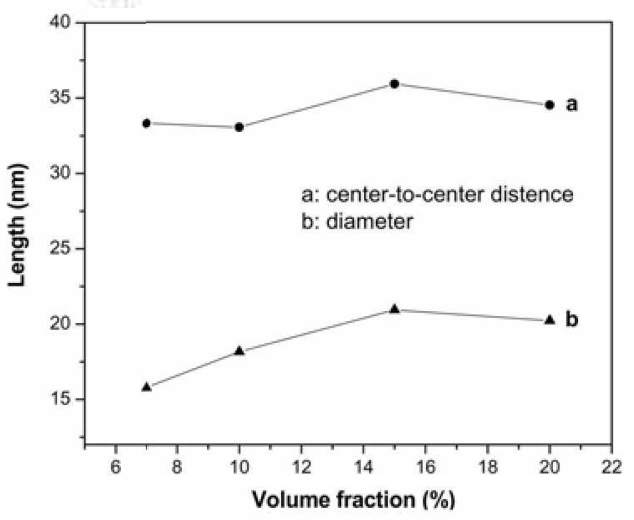

Figure 5. FESEM images of arravs of $\mathrm{Al} / \mathrm{TiO}_{2}$ nanoparticles obtained from the hybrid PS- $b-\mathrm{PEO} / \mathrm{HAuCl}_{4} / \mathrm{SG}$ films after removal of the block copolymer matrix by exposing the samples to UV light for 2 days in air: (a) $7.0 \%$ : (b) $10.0 \%$; (c) $15.0 \%$ : (d) $20.0 \%$. (e) The average diameter of $\mathrm{Au} / \mathrm{TiO}$ 2 nanoparticles, $D$, and the center-to-center distance between them, $d_{C-c}$, as a function of the amount of sol-gel precursors. The scale bar at lower left of each SEM image represents $100 \mathrm{~nm}$. 


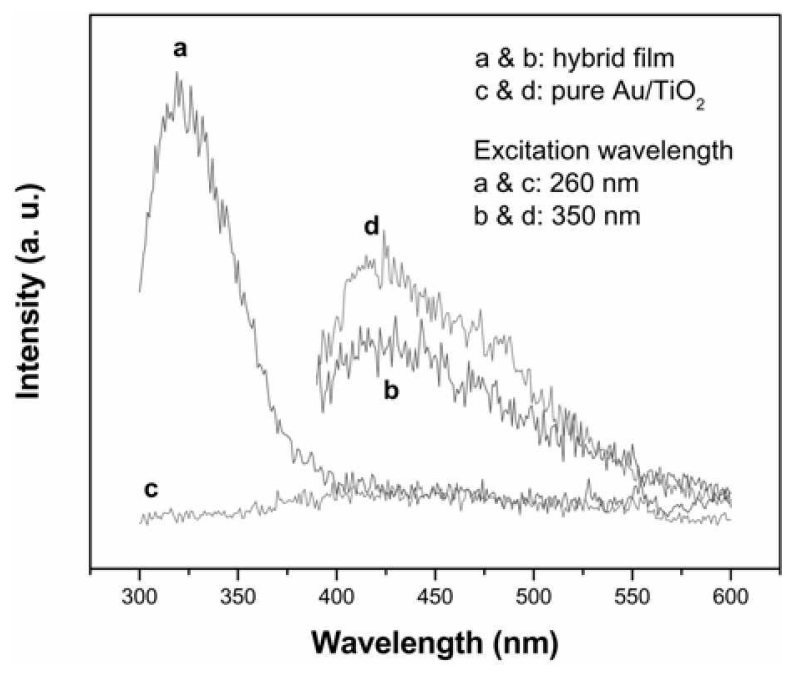

Figure 6. (a) and (b): PL spectra of the hybrid PS-b-PEO/HAuCl $/$ SG10 filln. (c) and (d): PL spectrunn from arrays of $\mathrm{AW} / \mathrm{TiO}$. composite nanoparticles obtained after removal of the PS- $b$-PEO template by deep UV irradiation. The excitation wavelength used in (a)-(c) is $260 \mathrm{~nm}$ and $350 \mathrm{~nm}$ in (b) and (d), respectively

the $\mathrm{PL}$ spectra of $\mathrm{TiO}_{2}$ nanoparticles. ${ }^{3{ }^{3} a}$ The physical origin of the fluorescence may be interpreted in terms of the emission from the radiative recombination of self-trapped excitons localized within $\mathrm{TiO}_{6}$ octahedra and oxygen vacancies ${ }^{38}$ It is worthwhile to note that the Au nanoparticles in the spincoated hybrid film exhibit a PL at about $320 \mathrm{~nm}$ with a photoexcitation wavelength at $260 \mathrm{~nm}$. which may be assigned to radiative recombination of Fermi level electrons and $s p$ or $d$-band holes. ${ }^{39}$ After removal of the block copolymer matrix, the PL spectrum of the arrays of $\mathrm{Au} / \mathrm{TiO}$ : composite nanoparticles exhibits only a broadband with a main peak centered at about $420 \mathrm{~nm}$ and $455 \mathrm{~nm}$ with photoexcitation at $260 \mathrm{~nm}$ and $350 \mathrm{~nm}$. respectively. This may be attributed to the structural changes of the $\mathrm{Au}$ and $\mathrm{TiO}=$ nanoparticles. It can be deduced from Figure 6 that the $\mathrm{Au}$ and $\mathrm{TiO}_{2}$ nanoparticles exist in separate domains each other in the hy brid films based on the observation that the PL emission from both the $\mathrm{TiO}_{2}$ and $\mathrm{Au}$ nanoparticles in the hybrid film can be observed. However. the $\mathrm{Au}$ and $\mathrm{TiO}_{2}$ will contact each other if the block copolymer template is removed. Under excitation, the Au nanoparticles are photoexcited due to plasmon resonance. and charge separation occurs by the transfer of photoexcited electrons from the Au particle to the $\mathrm{TiO}_{2}$ conduction band ${ }^{\text {al }}$ Therefore. PL peak of Au nanoparticles does not appear independently form $\mathrm{Au} / \mathrm{TiO}_{2}$ composite nanoparticles under excitation wavelength of 260 ım. In comparison with $\mathrm{TiO}_{2}$ nanoparticles, no noticeable difference was found from $\mathrm{Au} / \mathrm{TiO}_{2}$ composite nanoparticles. which is consistent with the previous results. ${ }^{219.41}$

\section{Conclusions}

We presented a simple route to produce arrays of $\mathrm{Au} / \mathrm{TiO}_{2}$ composite nanoparticles using Au-loaded micelles of PS- $b$ PEO block copolymers as templates combining with sol-gel process. Sol-gel precursors could be selectively incorporated into the $\mathrm{PEO} / \mathrm{HAuCl}_{4}$ domains in the Au-loaded PS- $b$-PEO solution. After spin coating, organic/morganic hybrid films with dense arrays of inorganic domains containing $\mathrm{TiO}_{2}$ and Au embedded in an organic matrix were generated. The size of each nanoparticle and the characteristic spacing of the arrays could be controlled by varying the relative amounts of the SG precursors versus block copolymers. By removing the organic template with deep UV irradiation. arrays of pure $\mathrm{Au} / \mathrm{TiO}$ 2 composite nanoparticles could be obtained with controlled lateral scale on a substrate surface. The initial organic/morganic hybrid film and the $\mathrm{Au} / \mathrm{TiO}_{2}$ composite nanoparticles array exhibit different fluorescence emissions spectra. indicating that the $\mathrm{TiO}_{2}$ and $\mathrm{Au}$ keep their respective domains in the as-cast. initial films. This work demonstrates a simple, low-cost method with potential applications in photocatalysis. as energy conversion sensors, or as a model system to study the mechanism of photochemistry in nanopatterned media.

Acknowledgements. Dr. X. Li acknowledges the supports of the National Natural Science Foundation of China (20674030). Shandong Natural Science Foundation (Y2006B02) and the Doctorial Foundation of University of Jinan (B0541). This work was supported by the Seoul Research and Business Development Program (10816) and the Korea Research Foundation Grant funded by the Korean Government (MOEHRD. Basic Research Promotion Fund) (KRF-2006003-D00138). The authors are indebted to Jian Wei Chai at the Institute of Materials Research Engineering (IMRE) in Singapore for the XPS analysis, Gunnar Glasser and Hansjorg Menges at the Max Planck Institute for Polymer Research for the SEM and PL measurements. respectively.

\section{References}

I. (a) Linsebigler. A.: Lu. G.: Yates. J. T. Chem. Rev 1995. 95.735758. (b) Takob. M.: Levanon. H.: Kamat. P. V. Namo Lett. 2003. 3. 353-358. (c) Naoi. K: Ohko. Y: Tatsuma. T. J. Am. Chem. Soc. 2004. 126, 3664-3668. (d) Cozzoli, P. D.: Comparelli, R: Fanizza. E. Curr, M. L.; Agostrano, A.; Laub, D. J. Am. Chem. Soc. 2004. 126. $3868-3879$

2. (a) Rolison. D. R. Science 2003. 299. 1648-1701. (b) Sut1. B.: Vorontsoy. A. V.: Sminniotis. P. G. Lamgmin 2003. 19.3151-3156. (d) Soejima. T.: Tada. H.: Kawahara. T.: Ito. S. Lamgnuir 2002. 18. $4191-4194$

3. (a) Willner. 1.: Patolsky, F.: Wasserman, J. Angew. Chem. Int Ed. 2001. 40. 1861-1864. (b) Cao. Y: Banin, U. Angew. Chem. Iht Ed. 1999. 38. 3692-3694. (c) Wang. Z.: Chumanov. G. Ad h Mater: 2003. 15. 1285-1289. (d) Yu. S:: Yoshimura. M. Adv Himet. Mater 2002. 12.9-15

4. (a) Schneider. J. J. Adv . Hater 2001. 13, 529-533.

5. (a) Moser. W. R. Adranced Catalysis and Nanostructured Materials, Academic Press: San Diego. CA. 1990. (b) Schiavello. M. Photocatalysis and Eminoment. Trends and Applications: Kluwer Press: The Netherlands. 1988. (c) Pelizzetti. E.: Serpone. N. Photocatalusis: Findantentals and Apphications: Wiley: New York. 1989.

6. (a) Oregan. B:- Gratzel, M. Natwe 1991, 353. 737-740. (b) Diebold, U. Surf. Sci. Rep. 2003, 48, 53-229. (c) Matthews, R. W. J. Catal. 1988. 111. 264-272. 
7. Arnold. G. W. J. Appl. Phvs. 1975 . 16. 4466-4473

8. Tanahashi. I.: Manabe. Y: Tohda. T.: Sasaki. S.: Nakamura. A. J. Appl Phys. 1996. 79. 1244-1249.

9. (a) He. I.: Ichinose I. Fujikawa S: Kunitake. T.: Nakao. A. Chem. Mater 2002, It. $3493-3500$ (b) He. I.: Ichinose. I. Kunitake, T.: Nakao A. Langmir 2002. 18. 10005-10010.

10. (a) Pastoriza-Santos. I.: Kolttysh. D. S.: Mamedov. A. A.: Giersig. M.: Kotov. N. A.: Liz Marzan. L. M. Langmuir 2000. 16. 27312735. (b) Tom. R. T.: Nair. A. S.: Singh. N.: Aslam. M: Nagendra, C. L.: Philip, R.: Vijayamohanan. K: Pradeep. T. Langmir 2003. 19, $3439-3445$.

11. Kielbassa, S: Kinne. M.: Belmm, R. I. Langmir 2004, 20,66446650 .

12. (a) Schenhar. R.: Norsten. T. B.: Rotello. V. M. Adw: Mater. 2005 17. 657-669. (b) Bockstaller. M. R.: Kolb. R.: Thomas. E. L. Add: Hater. 2001 , 13. 1783-1786.

13. (a) Bullen. H. A.: Gamett, S. J. Hamo Lett. 2002. 2. 739-745. (b) Moritz. T.: Reiss. I.: Diesner. K.: Su. D.: Chemseddine, A. J. Phws. Chem. B 1997. 101. 8052-8053. (c) Burnside. S. D.: Shiklover. V: Barbe. C.: Comte. P.: Arendse. F.: Brooks. K: Grätzel. M. Chent. Water. 1998. 10.2419-2425.

14. Hamley, I. W. The Phnsics of Block Copohmers: Oxford University Press: New York. 1998.

15. Fredrickson. G. H.: Bates. F. S. Amm. Rev. Mater. Sci. 1996, 26. $501-550$.

16. Fasolka. M. J.: Mayes. A. M. Amm. Rev Mater: Res. 2001. 31. 323-355.

17. Hashimoto, T.: Shibasma, M:- Fujimura. M: Kawai, H. Block Copolymers. Scrence and Techolog" Meier. D. J., Ed.: Harwood Academic: London, 1983; pp 63-108.

18. Lazzari. M.: Lopez-Quintela. M. A. Att: Hoter. 2003. 15. 15831594

19. (a) Hamley. I. W. Angew: Chem. Int Ed 2003. 12. 1692-1712. (b) Hamler I. W. Namotechologv 2003. 14, R39-R54.

20. Soler-Illia, G. J. de A. A.; Crepaldi, E. L.; Grosso, D; Sanchez, C. Cum Opin. Goll hater. Sci. 2003. 8, 109-126.

21. (a) Förster. S.: Plantenberg. T. Angew. Chent. Int. Ed. 2002. H1, 688-714. (b) Förster. S.: Konrad. M. J. Mater: Chem. 2003. 13. 2671-2688. (c) Förster. S.: Antonietti. M. Adk: Hater. 1998. I0. 195-217. (d) Kleitz, F.: Kim. T.-W.: Rvoo, R. Bull. Kor Chem. Soc. 2005, 26. 1653-1668. (e) Bae. J. Y.: Choi. S.-H.; Bae, B. S. Bull. Kor. Chem. Soc. 2006, 27. 1562-1566.

22. Park. C.: Yoon. J.: Thomas. E. L. Polvmer 2003. H. 6725-6760.

23. Segalman. R. E. M fater Si. Eng. R 2005 18. 191-226.

24. Thurn-Albrecht. T.: Schotter. J.: Kästle. G. A.: Emley. N.: Shibauchi. T: Krusin-Elbaum. L: Guarini. K: Black. C. T: Tuominen, M. T.: Russell T. P. Science 2000 290. 2126-2129.

25. Park M.: Harrison C.: Chaikin. P. M.: Register, R. A.: Adamson, D. H. Sciente 1997. 276, 1401-1404.

26. Urbas. A. M.: Maldovan. M.: DeRege. P.: Thomas. E. L. Ad Nater 2002. IH. 1850-1853.

27. Kim, D. H.: Lau, K. H. A.: Robertson, I. W. F; Lee. O. J.: Jeong.
U.: Lee. T. I.: Hawker. C. T.: Russell. I. P.: Kim. T. K.: Knoll. W Ad Hater. 2005. 17. 2442-2446

28. (a) Kästle. G.: Boyent. H.-G.: Weigl. F.: Lengl. G.: Herzog. T: Ziemann. P.; Riethmuller. S.: Maver, O.: Hartmann, C.; Spatz. J. P.: Möller M.: Ozawa. M.: Banhart, F; Garnier M. G.; Oelhaten. P. Ad. Funct. Mat. 2003, 13,853-861 (b) Spatz. J. P.: Mösser, S.: Hartman11. C.: Möller. M.: Heızog. T.: Krieger. M.: Boyen1. H.-G.: Ziemant1. P. Lamgnuir 2000. 16. 407-415. (c) Spatz. T. P: Roescher. A.: Möller. M. Adh: Mater 1996. 8.337-340.

29. (a) Li. X.: Lau. K. H. A.; Kim, D. H.; Knoll, W. Langmuir 2005. 21. 5212-5217. (b) Li, X.: Göring, P.: Pippel, E.: Steinhart, M. Kim. D. H; Knoll, W. Macromol Rapid Commun 2005, 26. 1173-1178.

30. (a) Kim. D. H.: Tia. X.: Lin. Z.: Guarini. K. W.: Russell. T. P. Ad Mater. 2004. 16. 702-706. (b) Kim. D. H.: Kim. S. H.: Lavery. K.: Russell, T. P. Namo Letters 2004 t, 1841-1844.

31. (a) Kim. D. H.; Sun, Z. C.: Russell, T. P.; Knoll, W.: Gutmann, J. S. Ad, Funct Mater, 2005. 15. 1-6. (b) Sun, Z.: Kim, D. H: Wolkenhauer. M.: Bumbul. G. G: Knoll. W: Gutmann. J. S. Chenthoshent 2006. 7. 370-378.

32. (a) Yang. P. D.: Deng. I.: Zhao. D. Y.: Fentg. P. Y.: Pine. D: Chmelka. B. F; Whitesides. G. M.: Stucky. G. D. Science 1998. 282. 2244-2246. (b) Yang, P. D.; Zhao. D. Y.; Margolese, D. I.; Chmelka. B. F; Stucky G. D. Nature 1998. 396, 152-155. (c) Britiker. C. T.: Lu. Y.: Sellinger. A.: Fat1. H. Adr: Mater. 1999. 11 . 579-585. (d) Soler-Illia. G. I. de A. A.: Sanchez. C.: Lebeau. B.: Patarin. J. Chem. Rev. 2002. 102. 4093-4138. (e) Göltner. C. G.: Henke. S.; Weissenberger, M. C.: Antonietti. M. Angew: Chem. Int. Ed. 1998.37.613-616

33. Haseloh, S.: Choi, S. Y.: Mamak. M.: Coombs, N.: Petrov. S. Chopra. N.: Ozinl. G. A. Chem. Contmitn. 2004. 13. 1460-1461.

34. Vagberg. L. J. M.: Cogan. K. A.: Gasto. A. P. Macrontolecules 1991. 2f. 1670-1677

35. (a) McKay. J. M.: Henrich. V. E. Surf. Sci. 1984, 137. 463-472. (b) Zimmermann. R.; Steiner. P.: Claessen, R.: Reinert, F.: Hufner, S. J. Electon Spec. Relat. Phenom. 1998. 96, 179-186.

36. (a) Brust. M.: Walker. M. J. Chem. Soc. Chem. Commm. 1994. 801-802. (b) Boyen. H. G.: Kästle. G. Science 2002. 297. 1533 1536. (c) Tuodkazis. K.: Juodkazyte. T.: Jasulaitiene. V: Lukinskas. A.; Sebeki, B. Electrochem. Connum. 2000, 2, 503-507.

37. Ouyang, M.; Yuan, C ; Muisener, R. J.: Boulares, A; Koberstein. J. T. Chem 1/ater 2000, 12, 1591-1596.

38. (a) Zhang. W. F.: Zhang. M. S.: Yin. Z.: Chen. Q. Appl. Phns. B 2000. 70. 261-265. (b) Tang. H.: Berger. H.: Schmid. P. E.: Léwy. F.: Burri. G. Solid State Conmum. 1993. 87. 847-850. (c) Lei. Y.: Zhang. L. D.: Meng. G. W.; Li, G. H.: Zhang. X. Y.: Liang, C. H: Chen. W: Wang, S. X. Appl. Plys. Lett. 2001, 78, $1125-1127$.

39. Wilcoson. J. P.: Martin, J. E.: Parsapour. F.: Wiedenman. B. Kelley. D. F. J. Chent. Phis 1998. 108.9137-9143.

40. Tianl. Y.: Tatsuma. T. J. Ant Chem. Soc. 2005. 127. 7632-7637.

41. Guo. Y-G.: Hu. J-S.: Liang. H.-P.: Want. L.-J.: Bai. C.-L. Ad : Funct. Hater 2005. 15. 196-202 